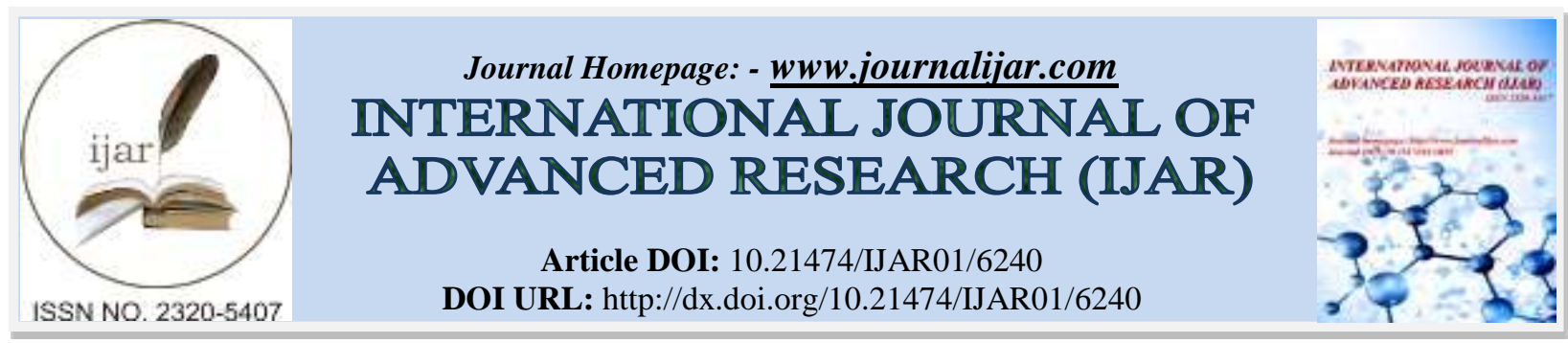

RESEARCH ARTICLE

\title{
OMENTAL INFARCTION: A RARE CAUSE OF AN ACUTE ABDOMEN IN THE EMERGENCY DEPARTMENT: A CASE REPORT.
}

Dr. Majdi S. Alzahrani ${ }^{1}$, Dr. Mohammad A. Samman ${ }^{2}$ and Dr. Ziyad A. Turkistani ${ }^{2}$.

1. Medical Intern, Faculty of Medicine, Umm Al-Qura University, Makkah, Saudi Arabia.

2. Medical Intern, Faculty of Medicine, Umm Al-Qura University, Makkah, Saudi Arabia.

\section{Manuscript Info}

Manuscript History

Received: 06 November 2017

Final Accepted: 08 December 2017

Published: January 2018

Key words:-

Omentum, infraction, Acute abdominal pain, computed tomography.

\section{Abstract}

Omental infarction is an unusual cause of acute abdominal pain in adults. Usually the condition similar to common causes of acute abdomen such as acute cholecystitis, acute appendicitis or acute pancreatitis. We report the case of a 50 -year-old women who presented with a 1-day history of severe right-sided abdominal pain mimicking acute appendicitis. Abdominal computed tomography scan revealed heterogeneous, localized, segmental omentum fat stranding infraction seen in the lower right quadrant, suspicious for omental infarction. She was started on conservative management with analgesics and hydration. She improved symptomatically and was discharged.

Copy Right, IJAR, 2018,. All rights reserved.

\section{Introduction:-}

Omental Infarction one of the rare causes of right abdominal pain can be either primary or secondary. Primary causes it was first reported by Eitel in $1899^{[1]}$.

Most patients present with acute right-lower quadrant pain, they are sometimes misdiagnosed as having appendicitis

${ }^{[2]}$ and a correct diagnosis is rarely made before surgery. but with the wide use of computed tomography (CT) in patients with acute abdomen, this rare disease could also be accurately diagnosed before surgery ${ }^{[3]}$.

Multiple aetiological factors are related to associated with OI, rendering infarcted omental tissue. Here we tend to report a case of idiopathic OI, given particular attention to the diagnostic and management considerations.

\section{Case Report:-}

A 50-year-old woman know case of diabetes mellitus, admitted to the emergency room with a history of worsening abdominal pain for 1 day ago. The condition has been started by sudden generalized abdomen pain later localized to the right lower quadrant since 2 weeks ago, the pain has great intensity exacerbated by activities reliving partially by analgesia. The pain was colicky in nature, progressive, no radiation, without a history of nausea, vomiting, anorexia, abdominal distention, constipation, diarrhea, change in bowel habit or urinary symptoms. There was no history of trauma or recent surgery, no history of constitutional symptoms, no history of blood transfusion and no history of previous admission of the same illness.

On physical examination, the patient was afebrile with a temperature of $36.4^{\circ} \mathrm{C}$ with stable vital signs. An abdominal examination revealed severe RIF tenderness, soft and lax, distended. Positive rebound tenderness was observed in the RIF and positive rovsing sign. The bowel sound was normal. 
The laboratory test showed white blood cell $12.3 \times 10^{9} / \mathrm{L}$, hemoglobin $12.4 \times 10^{9} / \mathrm{L}$, amylase $64 \mathrm{U} / \mathrm{L}$, lipase $122 \mathrm{U} / \mathrm{L}$, glucose $103 \mathrm{mg} / \mathrm{dL}$, renal function test, liver function test and electrolytes within normal range. Abdominal plain film erect and supine radiographs showed no abnormality. An abdominal ultrasound (US) was performed and showed the appendix could not be visualized, there is however minimal free fluid in the right iliac fossa with severe tenderness, no adnexal mass [Figure 1]. Computed tomography of the abdomen with IV and oral contrast was performed and showed the appendix was seen in the right lower abdomen, filled with fluid with no peri appendicular free fluid, fat stranding or lymphadenopathy, there's minimal fat stranding noted in the right lower omental fat measured craniocaudal $46.4 \mathrm{~mm} \times$ anteroposterior $27.0 \mathrm{~mm} \times$ width $45 \mathrm{~mm}$, no free fluid or air were seen [Figure $2]$.

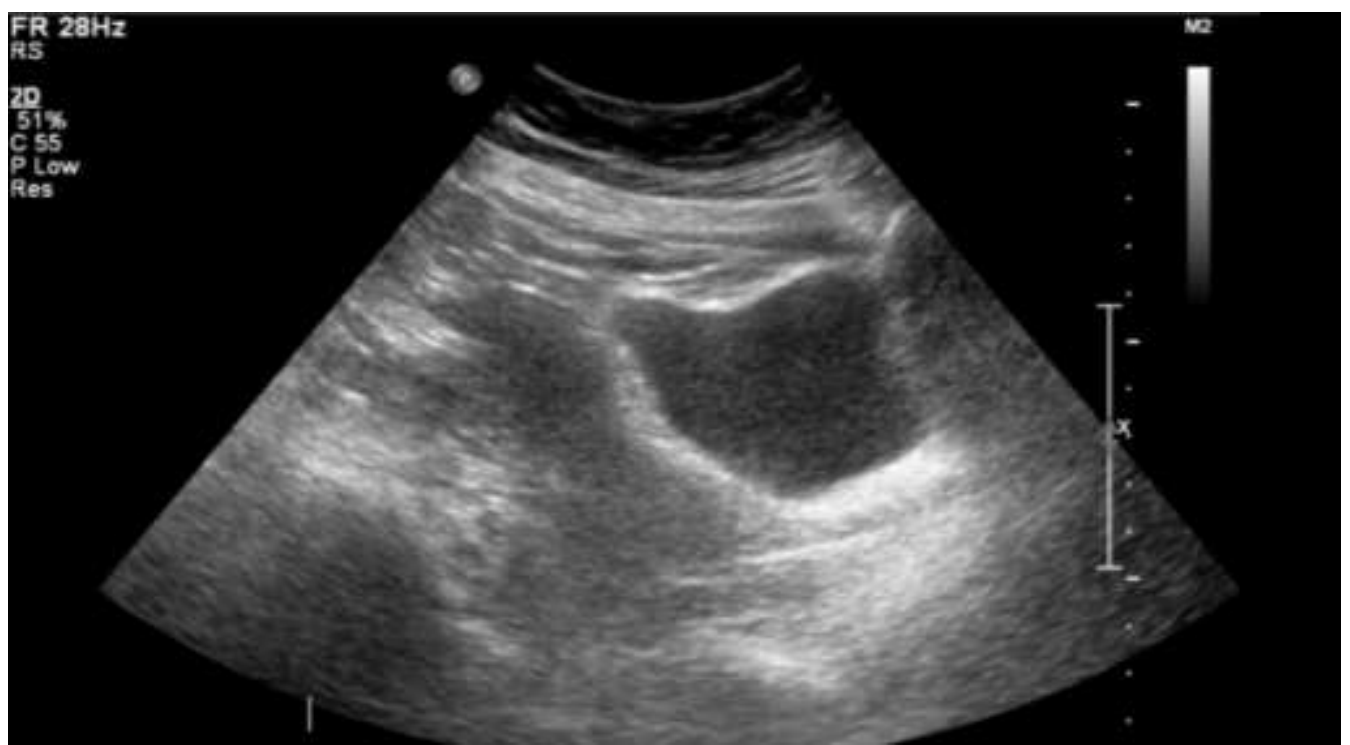

Figure 1:- Ultrasound of the abdomen minimal free fluid in the right iliac fossa (white arrow).

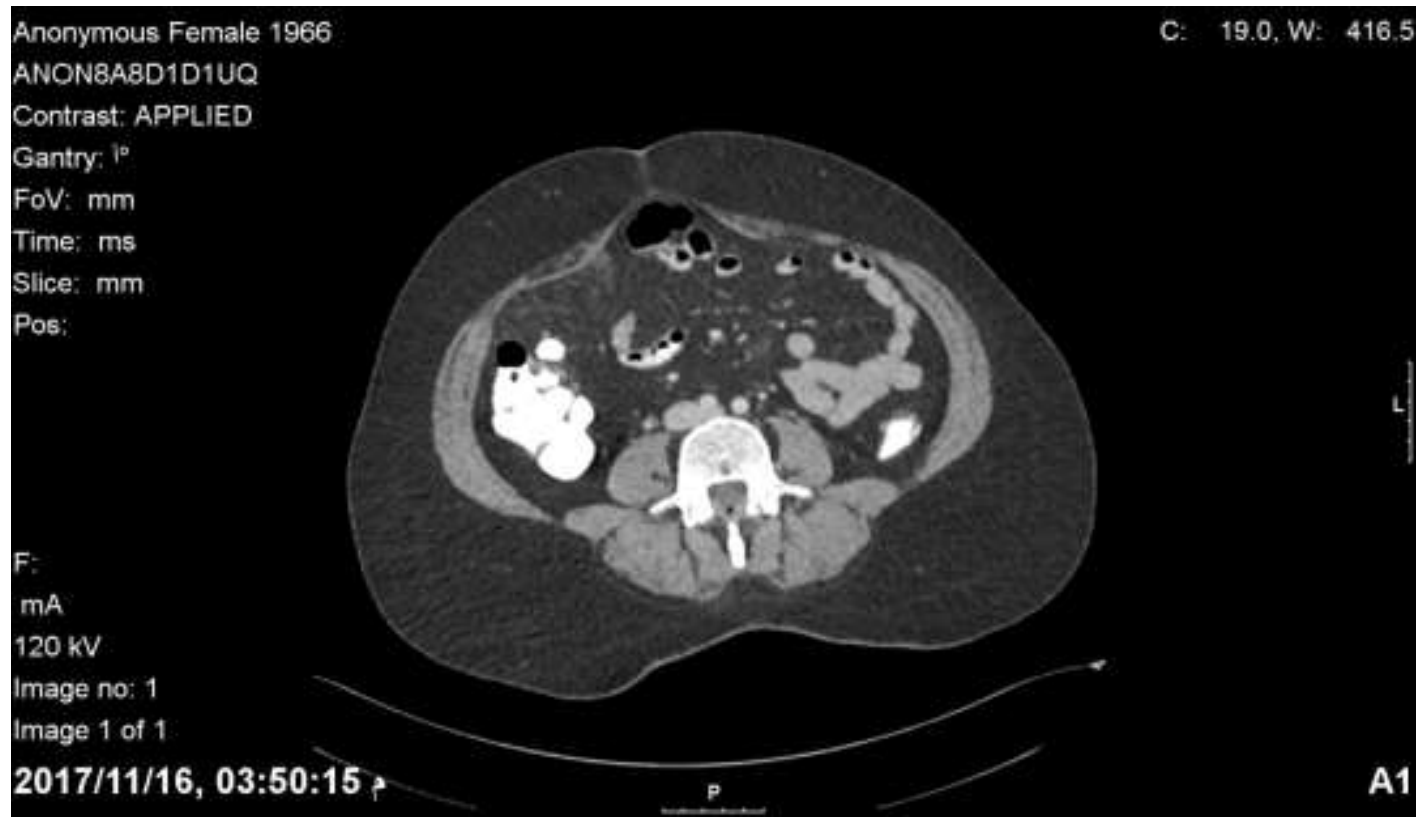

Figure 2:- heterogeneous, localized, segmental omentum fat stranding infraction seen in the lower right quadrant (white arrow).

The patient was admitted and kept NPO with intravenous fluid and analgesia. she was started $\mathrm{DM}_{\text {protocol: }} \mathrm{D}_{5}$ water $70 \mathrm{cc} / \mathrm{hr}$, regular insulin 6 unit, KCL $10 \mathrm{meq}$. Close observation to the patient with a prescription of Clexan $70 \mathrm{mg}$, Plasil $10 \mathrm{mg}$. After about 1 days, the patient still in pain, no pass stool, distended abdomen, as we decided to 
continues the same management until day 4, the patient condition improved, abdomen examination was normal except mild tenderness, laboratory investigation repeated showed no leukocytosis $9.25 \times 10^{9} / \mathrm{L}$, started a normal diet. She was doing well in the following days and was discharged with continues to clexan 40 mg for 10 days and OPD appointment after 2 weeks.

\section{Discussion:-}

Omental infarction is a rare cause of acute abdomen pain the estimated incidence $0.0016-0.37 \%$, usually being misdiagnosed as acute appendicitis ${ }^{[4.5]}$.

omental infarction it is categorized as primary or secondary. Primary omental infraction manifested without any pathological intra-abdominal signs, and a secondary omental infraction can be due to a secondary cause such as cysts, tumors, adhesions, hernia, trauma or surgical adhesion.

Primary omental infraction has exceptional imaging findings on CT and ultrasound. CT scan is the most essential method for the diagnosis of omental infarction. The most significant description of omental infraction is an ill-defined heterogeneous fat density associated with surrounding inflammatory changes ${ }^{[6]}$.In this current study, the CT showed the similar manifestation of omental infraction. Ultrasound is highly specific but low sensitive for diagnosing Primary omental infraction ${ }^{[7]}$.

omental infarction is often identified during surgery due to non-specific symptoms, an acute or subacute onset, and right abdominal pain, alongside with the broad use of imaging studies has improved the accurate diagnosis rate of the disease preoperatively. Because omental infarction runs a self-limited course, conservative care is advocated.

Nonoperative treatment with bed rest and anti-inflammatory medications are recommended before operating in cases that diagnosed or confirmed by CT or US and in patients hemodynamically stable ${ }^{[8]}$. In our case, this approach was applied.

Surgical exploration which is associated with low morbidity should be considered in your mind as it can be diagnostic and therapeutic in case of failure of conservative management, omental abscess, bowel obstruction, and in cases of uncertain diagnosis ${ }^{[9,10,11,12]}$.

\section{Conclusion:-}

An initial trial of conservative management, include analgesia and antibiotics, is advocated in patients that presented early in the course of the disease. If no improvement the Surgical exploration approach is required, Acute omental infarction is rare and for this reason, can be neglected if not thought about it.

\section{Conflict Of Interests:-}

The authors have no conflict of interests to disclose.

\section{Reference:-}

1. Eitel CG. Rare omental torsion. NY Med Rec. 1899;55:715.

2. Kerem M, Bedirli A, Mentes BB, Sakrak O, Pala I, Oguz M. Torsion of the greater omentum: preoperative computed tomographic diagnosis and therapeutic laparoscopy. JSLS: Journal of the Society of Laparoendoscopic Surgeons. 2005;9(4):494-6.

3. Lo C-P, Chen T-W, Liu H-D, Liu C-H, Chen C-Y, Yu C-Y. CT diagnosis of primary torsion of the greater omentum. European Journal of Radiology Extra. 2004;52:69-72.

4. Battaglia L, Belli F, Vannelli A, Bonfanti G, Gallino G, Poiasina E, et al. Simultaneous idiopathic segmental infarction of the great omentum and acute appendicitis: a rare association. World Journal of Emergency Surgery. 2008;3(1):30.

5. Balthazar EJ, Lefkowitz RA. Left-Sided Omental Infarction with Associated Omental Abscess. Journal of Computer Assisted Tomography. 1993;17:379-81

6. Steyaert H, Valla JS. Laparoscopic approach to primary infarction of the greater omentum. Surgical laparoscopy \& endoscopy. 1997;7(2):97-8. 
7. Ho CL, Devriendt H. Idiopathic segmental infarction of right sided greater omentum. Case report and review of the literature. Acta chirurgica Belgica. 2004;104(4):459-61.

8. Danikas D, Theodorou S, Espinel J, Schneider C. Laparoscopic Treatment of Two Patients with Omental Infarction Mimicking Acute Appendicitis. JSLS: Journal of the Society of Laparoendoscopic Surgeons. 2001;5(1):73-75.

9. Singh AK, Gervais DA, Lee P. Omental infarct: CT imaging features. Abdom Imaging 2006;31:54954.

10. Grattan-Smith JD, Blews DE, Brand T. Omental infarction in pediatric patients: sonographic and CT findings. Am J Roentgenol. 2002;178:1537-9.

11. Kavalakat AJ, Varghese CJ. Laparoscopic management of an uncommon cause for right lower quadrant pain: A case report. Cases Journal 2008;1:164.

12. AbdulAziz A, El Zalabany $\mathrm{T}$, Al Sayed AR, Al Ansari A. Idiopathic Omental Infarction, Diagnosed and Managed Laparoscopically: A Case Report. Case Reports in Surgery. 2013;2013:3. 